\title{
NET PRIMARY PRODUCTIVITY AND DRY MATTER IN SOYBEAN CULTIVATION UTILIZING DATAS OF NDVI MULTI-SENSORS
}

\author{
G. Rodigheri ${ }^{1}$, D. C. Fontana ${ }^{2}$, L. P. Schaparini², G. A. Dalmago ${ }^{3}$, J. Schirmbeck ${ }^{4}$ \\ ${ }^{1}$ CEPSRM, Post-Graduation Program of Remote Sensing, 91501970, Rio Grande do Sul, Brasil - grazielirodigheri@ gmail.com; \\ ${ }^{2}$ Dept. of Agronomy, Post-Graduation Program in Phytotechnics, 91540000, Rio Grande do Sul, Brasil - dfontana@ufrgs.br; \\ laura_pigatto@yahoo.com.br \\ ${ }^{3}$ Embrapa Trigo, 99001970, Rio Grande do Sul, Brasil - genei.dalmago@embrapa.br \\ ${ }^{4}$ UNIVATES, 95914014, Rio Grande do Sul, Brasil - schirmbeck.j@ gmail.com
}

KEY WORDS: Google Earth Engine, PAR, Remote Sensing, Agriculture.

\begin{abstract}
:
Net Primary Productivity (NPP) is an important indicator of vegetation growth status and ecosystems health. NPP can be estimated through remote sensing data, using vegetation indices such as NDVI. However, this index may show systematic differences when using several orbital sensors. Therefore, the objective of this paper was to compare the NDVI data obtained from different sensors and evaluate the impact over the soybean biomass and NPP estimates. NDVI data were recorded from 4 sensors, one on the field and others 3 orbitals sensors (Landsat 8/OLI, Sentinel 2/MSI and Terra/MODIS). Measured data on the field, Photosynthetically Active Radiation (PAR) and Dry Matter (DM), were used to modeling the total DM and also NPP. The NDVI data from different sensors showed differences throughout the cycle, but compared to the reference data there was a correlation greater than 0.84 . The DM presented a correlation of 0.91 with the field measured MS data while the NPP presented differences of up to $240 \mathrm{gC} / \mathrm{m}^{2} / \mathrm{month}$ from in relation to the reference data. Therefore, NDVI obtained from multiple sensors can be used to estimate NPP for surface analysis. However, for more consistent evaluations, a function of adjustment between the NDVI sensor data and NDVI reference data is required, so that the NPP estimation be better correlated to the actual data.
\end{abstract}

\section{INTRODUCTION}

Accurate estimates of crop production are crucial especially in developing countries (Sivasankar et al, 2018), and the yield of these crops is mainly linked to the dynamics of biophysical variables during the growth season (Basso, Cammarano, Carfagna, 2013). One of the indicators of crop yield that has gained prominence in scientific studies in recent years is NPP (Bao et al, 2016; Potter, Klooster, Genovese, 2012; Haberl et al, 2004; Potter , 1993), which represents the amount of carbon fixed by plants through photosynthesis per unit of time and space (Potter, Klooster, Genovese, 2012; Yu et al., 2009). NPP is not only an important indicator of vegetation growth status and ecosystem health, but exerts an important influence on the global biosphere carbon cycle (Potter, Klooster, Genovese, 2012).

NPP is considered a key component for a wide range of studies on ecological processes (Running et al., 2004). The importance of knowing the NPP of terrestrial ecosystems is linked to the main role played in the carbon cycle and its energy flow (Rosa, Sano, 2013). Thus, quantitative estimates of NPP at regional to global scales are essential for understanding changes in ecosystem structure and function, predicting terrestrial carbon cycle trends (Yu et al., 2009) and determining their sustainable use.

Remote sensing is now considered a powerful tool and unique data source for characterizing vegetation structure and development globally, and has played an increasing role in NPP estimates of ecosystems (Bao et al, 2016). The relationship between remote sensing and biophysical variables can be done by simple sensor bands and also by applying vegetation indices (Monteiro et al., 2013). Vegetation indices are often used to estimate vegetation parameters, and their physical basis is attributed to the high absorption of solar radiation by chlorophyll and their scattering by leaves in the red and near infrared spectral regions, respectively (Gates et al., 1965).

Among a variety of indices, the Normalized Difference Vegetation Index (NDVI) has been widely used. The NDVI, calculated by the difference of near infrared (NIR) and red (R) reflectances and normalized by their sum, is one of the most commonly indices used to monitor plant status. This index also has a high correlation with vegetation cover percentage (Purevdorj et al., 1998) and green leaf biomass (Gitelson, Gritz, Merzlyak, 2003). In addition, it can be used to estimate biophysical parameters, such as leaf area index (LAI) and the fraction of photosynthetically active radiation that is absorbed (APAR) (Myneni, Williams, 1994), or even to compose models for crop yield estimations (Monteiro et al., 2013; Raun et al., 2001; Dorigo et al., 2007, Martorano, 2007).

Sensors aboard different platforms may provide NDVI, but it is important to consider that there are differences in central wavelengths or bandwidths used for index calculation (Kim et al., 2010). In addition, the index value may be influenced by several other factors, which may introduce interpretation noise when multi-sensor NDVI data are used in change detection studies. In this way, Chander (2013) warned that difference in remotely detected data may not correspond to changes in the surface, but partly due to differences in provenance in the sensors. Also Teillet et al. (2007) addressed this theme, pointing out that data from different sensors cannot be directly compared, due to differences in sensor response functions. Therefore, in multi-decade environmental studies, NDVI data from multiple sensors should be processed initially in an effort to generate a consistent spatial, temporal and spectral data set (Pahlevan et al., 2016). These analyzes provide assurance that these data can be used to reliably estimate biophysical parameters. 
However, in crops studies there is often the need to merge data from more than one sensor to characterize the temporal and spatial variability of a given crop. This is because many sensors have low temporal resolution and also the excessive amount of clouds in some periods. Thus, it is essential to evaluate and compare the differences between data obtained from multiple sensors for a better understanding and characterization of vegetation and its spatio-temporal changes through biophysical parameters. Based on this, we obtained NDVI data from four different sensors (involving one field- sensor and three orbital sensors), in order to compare the NDVI data and evaluate their impact over the soybean biomass and NPP estimation.

\section{MATERIALS AND METHODS}

The data included in this study and used as reference were obtained from a soybean experiment conducted in Carazinho / RS during the 2017/2018 crop season (Figure 1).
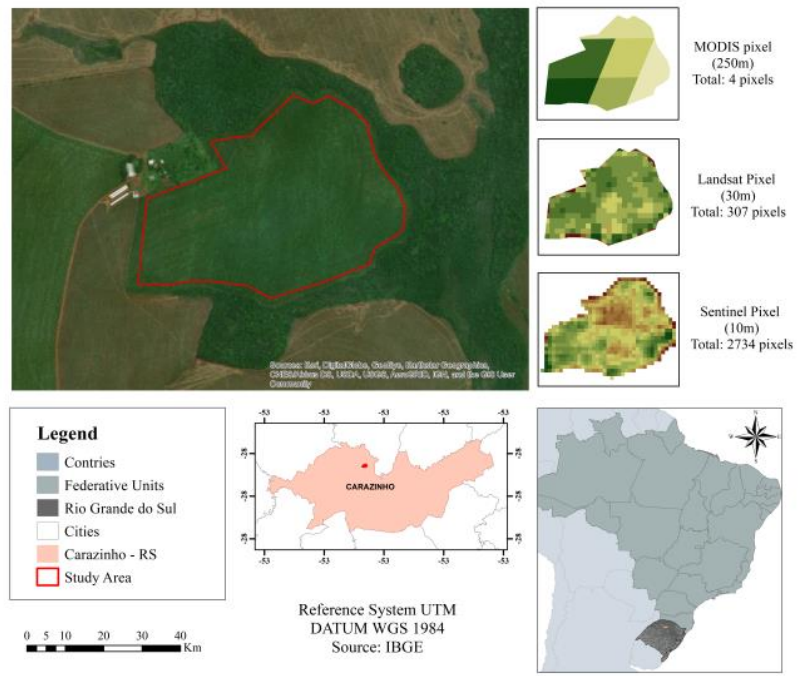

Figure 1. Study area location and pixel size of each orbital sensor used. Carazinho/RS, 2017/18.

\subsection{Reference measured data}

During the field experiment, data were measured for the components of incident (PARinc), transmitted (PARt) and reflected (PARref) photosynthetically active radiation. These measurements were performed using a set of bars equipped with amorphous silicon cell sensors (Pandolfo, 1995), installed in parallel and spaced at a distance of $0.20 \mathrm{~m}$. From these, the absorbed PAR (APAR) was determined through equation 1:

APAR $=$ PARinc - PARt - PARref

Reference NDVI data was measured in order to adjust functions for the estimation of the FPAR component. The index was obtained from incident (SRS NDVI Hemispheric) and reflected (SRS NDVI with Vision Limiter) radiation sensors in the red $(0.6$ to $0.7 \mu \mathrm{m})$ and near infrared (NIR) $(0.805$ to $0.815 \mu \mathrm{m})$ spectrum. These spectral sensors were attached to a mast, at a height of $1 \mathrm{~m}$ above the top of the canopy, adjustable throughout the cycle (Figure 2). In order to obtain an average between the soil and soy mixture present in the cultivation, they were installed in different positions in the experimental area.

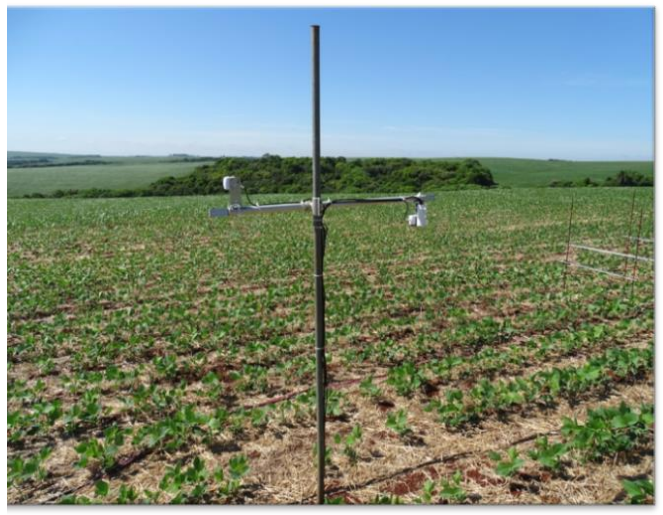

Figure 2. Incident (SRS NDVI Hemispheric) and reflected (SRS NDVI with Vision Limiter) radiation sensors installed in the experimental area. Carazinho/RS, 2017/18.

The accumulated MS was determined weekly from the collection of $0.5 \mathrm{~m}$ from a plant line. Four samples were taken in each collection. The green biomass of each sample was placed in paper packaging and placed for drying in a proper oven for drying plant material at a temperature of $70^{\circ} \mathrm{C}$ until reach constant mass. DM was quantified and calculated for $\mathrm{g} \mathrm{m}-$ 2. This procedure was adopted from the emergence of plants at the end of the cycle. At this time, after the physiological maturation of the pods, four biomass samples of $9 \mathrm{~m}^{2}$ were made to determine the grain yield.

\subsection{Data obtained from satellites}

In addition to reference NDVI, NDVI data were obtained from different orbital sensors for the 2017/2018 crop season (Table 1). For this purpose, the most used sensors in agricultural studies were chosen, such as Landsat, MODIS and Sentinel, due to their availability on the Google Earth Engine platform.

\begin{tabular}{|c|c|c|c|c|c|}
\hline \multirow{2}{*}{ Satellite } & \multirow[b]{2}{*}{$\begin{array}{l}\text { Sensors/ } \\
\text { Products }\end{array}$} & \multicolumn{2}{|c|}{ Spetral Resolution } & \multirow[b]{2}{*}{$\begin{array}{c}\text { Spatial } \\
\text { Resolution }\end{array}$} & \multirow[b]{2}{*}{$\begin{array}{c}\text { Number of } \\
\text { pixels }\end{array}$} \\
\hline & & Bands & Wavelanght & & \\
\hline \multirow{2}{*}{ Sentinel 2} & \multirow{2}{*}{ MSI } & B4-Red & $0,64-0,68$ & \multirow{2}{*}{$10 \mathrm{~m}$} & \multirow{2}{*}{2734} \\
\hline & & B8 - NIR & $0,77-0,90$ & & \\
\hline \multirow{2}{*}{ Landsat 8} & \multirow{2}{*}{ OLI } & B4-Red & $0,64-0,67$ & \multirow{2}{*}{$30 \mathrm{~m}$} & \multirow{2}{*}{307} \\
\hline & & B5 - NIR & $0,85-0,88$ & & \\
\hline \multirow[b]{2}{*}{ Terra } & \multirow{2}{*}{$\begin{array}{c}\text { MODIS - } \\
\text { MOD13Q1 }\end{array}$} & B1-Red & $0,62-0,67$ & \multirow[b]{2}{*}{$250 \mathrm{~m}$} & \multirow[b]{2}{*}{4} \\
\hline & & B2 - NIR & $0,84-0,87$ & & \\
\hline
\end{tabular}

Table 1. Spectral and spatial resolution of the sensors used and total pixels present in the study area of each sensor. Carazinho/RS, 2017/18

To obtain NDVI data from the orbital sensors, the Google Earth Engine platform was used. The programming was performed using the JavaScript language on the programming platform and the GEE cloud processing, called Code Editor.

Cloud filters were applied to each imported collection and then NDVI (Equation 2) was calculated from the reflectances in the NIR and Red bands, as proposed by Rouse et al. (1973).

$$
N D V I=\frac{\rho_{N I R}-\rho_{R E D}}{\rho_{N I R}+\rho_{R E D}}
$$

For NDVI values of orbital sensors, the average value of the pixels covering the entire study area for each of the 3 satellites was generated. These data, combined with the surface sensor 
NDVI data, were graphically presented and used for the characterization of the 2018 soybean temporal profile. In addition, we analyzed the differences in NDVI values associated with the different sensors, for data intervals of 15 days, in order to match the dates of images.

Linear regression equations were also applied between the reference measured NDVI values and the NDVI values from the three orbital sensors. From these equations, the NDVI values of the different orbital sensors were adjusted.

\subsection{DM and NPP estimates}

For the estimation of DM, an adaptation of the concept developed by Montheith (1972) was used (Equation 3), considering biomass production as the product of Photosynthetically Active Absorbed Radiation (APAR) by the efficiency of conversion of APAR to DM $(\mathrm{Ea})$ of these plants:

$\mathrm{DM}=\mathrm{APAR} * \varepsilon \mathrm{a}$

In this work, the value of $1.57 \mathrm{~g} / \mathrm{MJ}$ was assigned to Ea, which was determined for soybean cultivation under adequate water conditions and also management conditions similar to the one under study (Martorano, 2007). APAR was obtained through the equation 4 :

APAR $=$ FPAR $*$ PARinc

Where PARinc is the monthly accumulation of incident PAR, given in MJ.m-month ${ }^{-1}$ and FPAR is the fraction of PAR intercepted by plants.

An FPAR can be modeled as a function of NDVI and often assumes a linear relationship with NDVI (Huemmrich et al., 2010). In the present work a linear regression between the FPAR, obtained through the relationship between APAR and PARinc, and reference NDVI (Fig. 3), was adjusted. This equation was used to estimate or FPAR from the NDVI of the three orbital sensors used in the work.

Estimated DM data from equation 3 using reference NDVI dataset were compared with field-measured DM data over the cycle.

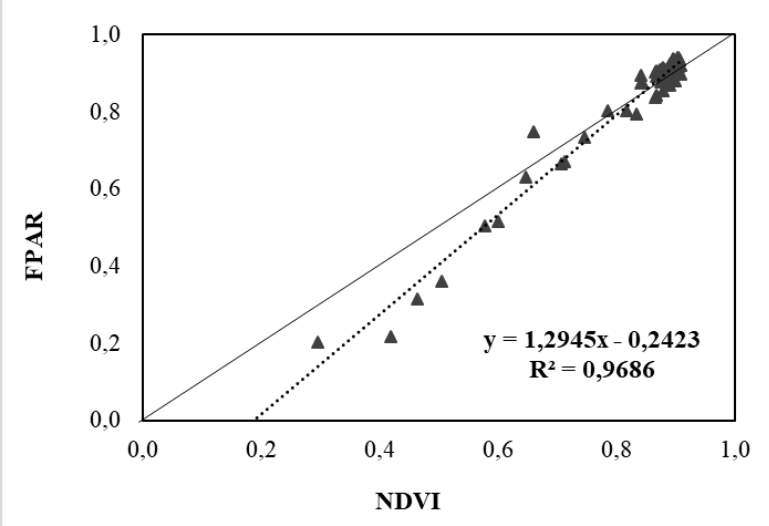

Figure 3. Linear regression between the Photosynthetically Active Absorption Radiation Fraction (FPAR) and the Surface Normalized Difference Vegetation Index (NDVI). Carazinho/RS, 2017/18.

Crop NPP was considered to be $40 \%$ of the total DM produced during the crop cycle (Pillon, Mielniczuk, Neto, 2004). NPP values were calculated using reference and orbital NDVI data as well as reference adjusted NDVI data. This last analysis aimed to verify the impact of differences in NDVI values from various sources on NPP estimation.

\section{RESULTS AND DISCUSSIONS}

\subsection{NDVI of the different sensors}

The NDVI data presented a similar pattern for the different used sensors, consistently representing soybean growth and development during the growing season. The cycle began at the end of November, when NDVI was low, followed by a rapid increase during December. From the beginning of January, the maximum NDVI values were reached, which remained constant until the end of February, characterizing the period of maximum green biomass in the crop. Soon after, it is possible to observe the decrease of NDVI values as a function of the onset of crop senescence. The highest similarity of NDVI data from the different sensors occurred from early January until the end of February, when NDVI data was saturated. Under conditions of higher biomass density, an absorption peak occurs in the red band (Povh et al, 2008), while infrared reflectance remains stable saturating the index.

The NDVI profile for each sensor presented an expected pattern and already observed in several studies for soybean cycle in the region (Fontana, Potgieter. Apam, 2007; Santos et al., 2014). Despite the similarity, it can be observed that there are variations in NDVI values from one sensor to the other, especially in the early and late crop periods. This is because each sensor has different characteristics and configurations (Table 1), and even for spectral bands designed to observe the same region of the electromagnetic spectrum, the result is relative spectral response functions that differ significantly between sensors (Teillet, Fedosejevs, Thome, 2004). Despite these differences, most of these indices were originally designed for broadband sensors, and therefore the broad spectral characteristics of vegetation in the red and near infrared regions allow these indices to transfer well between sensors of different bandwidths and positions (Cundill et al, 2015).

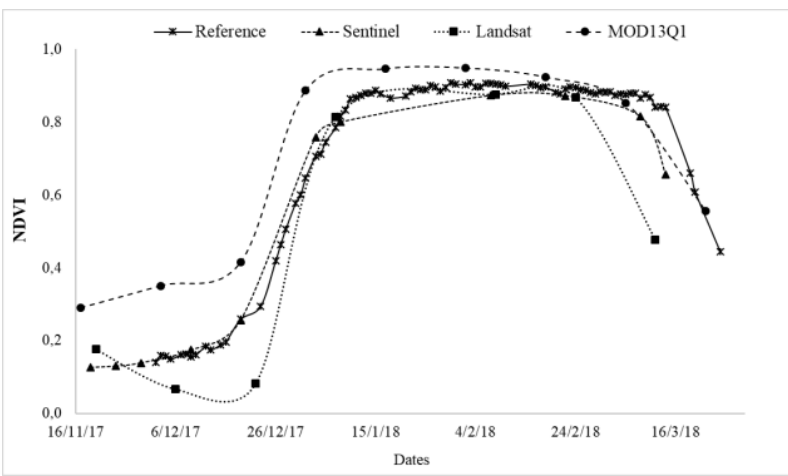

Figure 4. Normalized Difference Vegetation Index (NDVI) data during the Soybean Crop 2017/2018, for the different sensors used. Carazinho/RS, 2017/18

A greater difference from MOD13Q1 data to the other sensors is observed precisely in the initial period of crop growth. Most likely this is due to spectral mixing within the pixel, as the MODIS sensor has a moderate spatial resolution compared to the high resolution of Sentinel 2 and Landsat 8 (Table 1). However, this difference does not affect the relationship between the NDVI data from the MOD13Q1 and the measured data in the crop, with a high $\mathrm{R}^{2}$ of approximately 0.95 . This high 
association occurs because during the final stage of the crop cycle, the MOD13Q1 came closest to the crop data (Fig. 4). The main advantage of using MODIS sensor data is the availability of products with quality and temporal frequency adequated for crop monitoring, minimizing the difficulties in obtaining spatiotemporal profiles of crop areas due to cloud cover (Santos et al., 2014).

Even though Sentinel 2 and Landsat 8 satellites have very similar configurations, the difference in their NDVI from the measured data was high. Possibly the low temporal resolution of Landsat and, consequently, the lack of images for a longer period of time, due to the large cloud coverage during the crop development period, was the cause of the observed differences in relation to field data.

Despite these differences, the data from the different sensors presented a high correlation with the field measured data with minimum $\mathrm{R}^{2}$ of 0.78 and RMSE 0,18 . Nevertheless, due to the low temporal resolution (low availability of images during a crop season) and the high probability of cloud incidence during the crop development period, it is convenient to use the MOD13Q1 product to better characterize the crop growth profile, or the fusion of data from different sensors by establishing functions between them. These functions are therefore expected to make viable the integrated NDVI use of these sensors throughout the soybean cycle (Fig. 6).

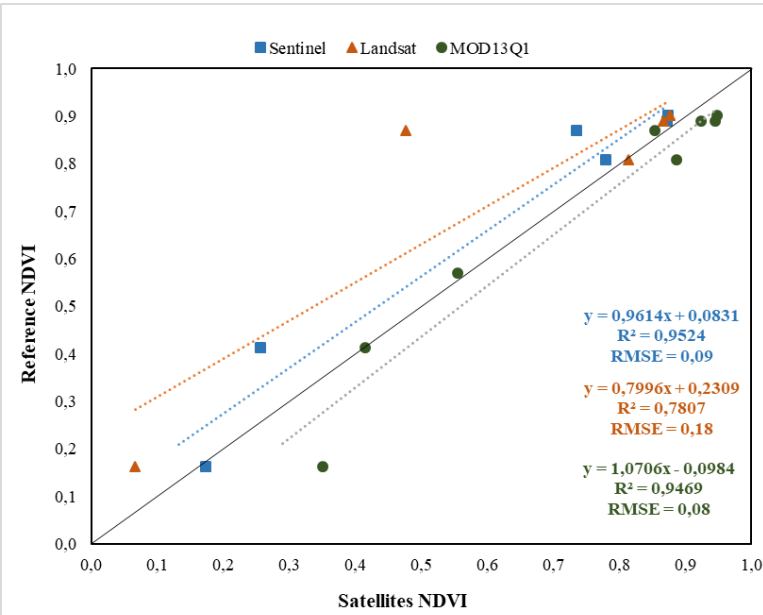

Figure 5. Normalized Difference Vegetation Index (NDVI) data for soybean crop obtained from different orbital sensors compared to surface measured data. Carazinho/RS, 2017/18

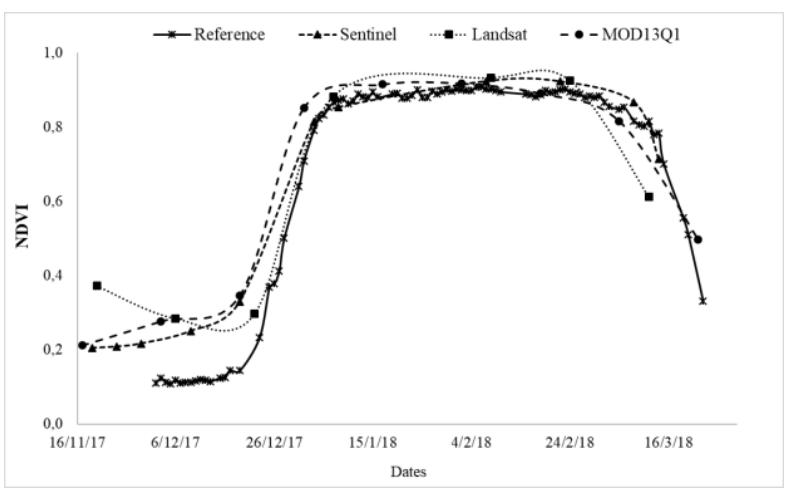

Figure 6. Normalized Difference Vegetation Index (NDVI) data for soybean crop obtained by functions of the reference data. Carazinho/RS, 2017/18

\subsection{DM and NPP estimated by different sensors}

Analyzing only the surface measured data, it is verified that the DM estimated by equation 3 presented a high correlation with the field measured data, indicating that the proposed method is robust and can be used in the biomass estimates of agricultural crops (Fig. 7). Moreover, it is also inferred that the Ea used in the estimate adequately represented the efficiency of conversion of APAR to DM, considering the appropriate water conditions that were verified during the study crop season. When water restrictions occur, however, it is recommended to evaluate the adequacy of this coefficient, or even to introduce coefficients that express such restrictions.

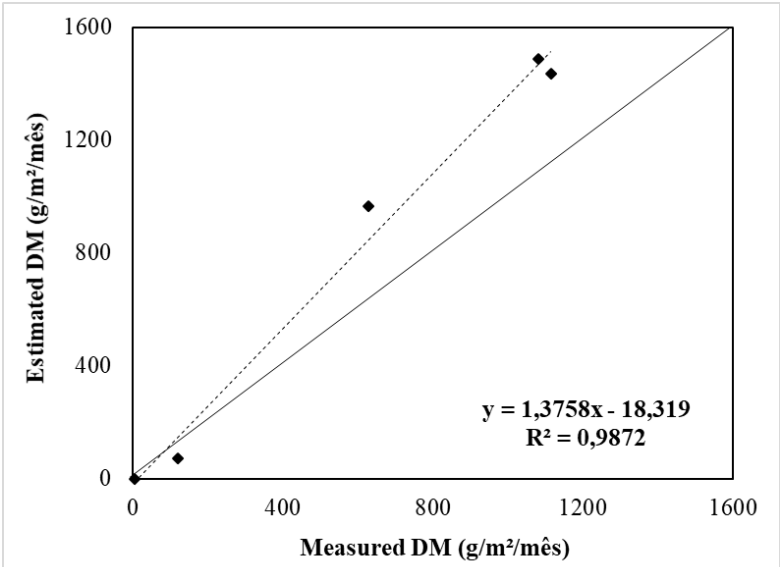

Figura 7. Linear regression between soybeans dry matter (DM), estimated by Montheith's adapted equation (1972), and fieldmeasured Carazinho/RS, 2017/18

By expanding the analysis including data obtained from orbital sensors, it was possible to analyze the impact of differences in NDVI values on NPP estimates. When a monthly analysis is observed, NPP data were similar, especially in the months of highest biomass production, which are January and February. However, by analyzing only the total NPP produced at the end of the soybean cycle, there are differences between the sensors, with the largest difference occurred in the Landsat satellite. The data from this sensor underestimated the total cycle NPP estimate, while the MOD13Q1 and Sentinel data were the closest to the field data (Table 2).

Platform and sensor combinations are known to differ in their temporal, spatial and spectral configuration. Regarding the spectral configuration, both Landsat and Sentinel specifications are designed so that there is a significant correspondence between the corresponding spectral bands. However, some differences can be expected in the recorded radiometric values (Mandanicci, Bitteli, 2015). Clearly, the importance of these differences depends on the application and the approach, since according to D'Odorico et al. (2013), methods based on physical quantities through remote sensing reflectance or empirical approaches based on multispectral indices, are more affected by the problem. 


\begin{tabular}{ccccccccc}
\hline & Month & \multicolumn{4}{c}{ NPP } & \multicolumn{4}{c}{$\begin{array}{c}\text { Difference between satellite and } \\
\text { reference estimated NPP }\end{array}$} \\
\hline & & Reference & Sentinel & Landsat & MOD13Q1 & Sentinel & Landsat & MOD13Q1 \\
Estimated & NOV & 0,0 & $-4,9$ & $-1,0$ & 9,0 & $-4,9$ & $-1,0$ & 9,0 \\
NPP & DEC & 28,9 & 9,8 & $-40,1$ & 69,2 & $-19,1$ & $-69,0$ & 40,3 \\
(g/m²/month) & JAN & 385,8 & 345,6 & 365,3 & 425,5 & $-40,2$ & $-20,5$ & 39,6 \\
& FEB & 574,4 & 556,2 & 555,2 & 607,1 & $-18,2$ & $-19,2$ & 32,7 \\
& MAR & 595,5 & 519,0 & 273,7 & 489,5 & $-76,5$ & $-321,7$ & $-105,9$ \\
Estimated & NOV & & 2,0 & 16,2 & 2,1 & 2,0 & 16,2 & 2,1 \\
NPP with & DEC & & 36,3 & 36,5 & 43,9 & 7,4 & 7,6 & 15,0 \\
ajusted & JAN & & 376,5 & 404,9 & 405,8 & $-9,3$ & 19,1 & 20,0 \\
NDVI & FEB & & 596,3 & 600,8 & 580,9 & 21,8 & 26,4 & 6,5 \\
(g/m²/month) & MAR & & 570,7 & 401,9 & 443,5 & $-24,7$ & $-193,6$ & $-152,0$ \\
\hline
\end{tabular}

Table 2. Net Primary Productivity (NPP) of soybeans estimated using Normalized Difference Vegetation Index (NDVI) data obtained from different sensors and estimated NPP from NDVI adjusted data through equations. Carazinho/RS, 2017/18.

\section{CONCLUSIONS}

The NDVI data of the different sensors are adequate to represent the temporal profile of soybean crop. Even with a lower spatial resolution, the MOD13Q1 product presents better results, mainly due to the quality and temporal frequency of the data.

The method adapted to estimate DM is suitable and can be used in soybean crop fields under adequate water conditions. Differences in the NPP estimation of the different sensors are mainly due to the low amount of images for Landsat and Sentinel sensors to represent NDVI variations during the crop season.

It is recommended to use combined data from some satellites for a better estimate of NPP, as using only one satellite may not represent actual productivity over the cycle.

\section{ACKNOWLEDGEMENTS}

We thank CAPES, UFRGS and Embrapa Trigo.

\section{REFERENCES}

Basso, B., Cammarano, D., Carfagna E., "Review of crop yield forecasting methods and early warning systems," Report presented to First Meeting of the Scientific Advisory Committee of the Global Strategy to Improve Agriculture and Rural Statistics FAO, Headquarters, Rome, Italy. pp. 1-56, 2013.

Bao, G. et al., 2016. Modeling net primary productivity of terrestrial ecosystems in the semi-arid climate of the Mongolian Plateau using LSWI-based CASA ecosystem model. International Journal of Applied Earth Observation and Geoinformation, v. 46, p.84-93.

Cundill, S., et al.., 2015. Adjusting Spectral Indices for Spectral Response Function Differences of Very High Spatial Resolution Sensors Simulated from Field Spectra. Sensors, v. 15, n. 3, p.6221-6240.
D’Odorico, P., et al., 2013. "Experimental Evaluation of Sentinel-2 Spectral Response Functions for NDVI Time-

Series Continuity." IEEE Transactions on Geoscience and Remote Sensing 51 (3): 1336-1348.

Dorigo, W., et al., 2007. A review on reflective remote sensing and data assimilation techniques for enhanced agroecosystem modeling. International Journal of Applied Earth Observation and Geoinformation, v.9, p.165-193.

Fontana, D. C.; Potgieter, A.; Apan, A., 2007. Assessing the relationship between shire winter crop yield and seasonal variability of the MODIS NDVI and EVI images. Applied GIS, v.3, p.1-16.

Chander G. et al., 2013. "Applications of spectral band adjustment factors (SBAF) for cross-calibration", IEEE Trans. Geosci. Remote Sens., vol. 51, no. 3, pp. 1267-1281.

Gates, D. M., et al., 1965. Spectral properties of plants. Applied Optics, v.4, p.11-20.

Gitelson, A.; Gritz, Y.; Merzlyak, M., 2003. Relationships between leaf chlorophyll content and spectral reflectance and algorithms for non-destructive chlorophyll assessment in higher plant leaves. J. Plant Physiol.

Haberl, H. et al., 2004. Human appropriation of net primary production and species diversity in agricultural landscapes. Agriculture, Ecosystems \& Environment, [s.1.], v. 102, n. 2, p.213-218.

Huemmrich, K.F. et al., 2010. Remote sensing of tundra gross ecosystem productivity and light use efficiency under varying temperature and moisture conditions. Remote Sensing of Environment, [s.1.], v. 114, n. 3, p.481-489.

Kim, Y., et al., 2010. Spectral compatibility of vegetation indices across sensors: band decomposition analysis with Hyperion data. J. Appl. Remote Sens.

Mandanici, E.; Bitelli, G., 2015. Multi-image and multisensor change detection for long-term monitoring of arid environments with Landsat series. Remote Sensing. 
Martorano. L. G. Padrões de resposta da soja a condições hídricas do sistema solo-planta-atmosfera, observados no campo e simulados no sistema de suporte à decisão DSSAT. Tese de doutorado em Fitotecnia, Universidade Federal do Rio Grande do Sul, Porto Alegre, 151p., 2007.

Monteiro, P. F. C. et al., 2013. Índices de vegetação simulados de diferentes sensores na estimativa das variáveis biofísicas do feijoeiro. Pesquisa Agropecuária Brasileira, [s.1.], v. 48, n. 4, p.433-441.

Monteith, J., 1972. Solar radiation and productivity in tropical ecosystems. Journal of Applied Ecology, vol. 9, n. 3, p.747-766.

Myneni, R. B. Williams, D. L., 1994. "On the Relationship between FAPAR and NDVI." Remote Sensing of Environment 49 (3): 200-211.

Pahlevan, N., et al., 2016. "Impact of Spatial Sampling on Continuity of MODIS-VIIRS Land Surface Reflectance Products: A Simulation Approach.huem" IEEE Transactions on Geoscience and Remote Sensing 55 (1): 183-196.

Pandolfo, C. Parâmetros básicos para uso na modelagem do rendimento de matéria seca em alfafa (Medicago sativa 1.). Dissertação (Mestrado) - Programa de Pós-Graduação em Fitotecnia, Faculdade de Agronomia, Universidade Federal do Rio Grande do Sul, Porto Alegre, 1995.

Pillon, C. N.; Mielniczuk J.; Neto, L. M. Ciclagem da Matéria Orgância em Sistemas Agrícolas. Embrapa Clima Temperado, Documento 125, 2004.

Teillet, P. M., Fedosejevs, G., Thome, K. J., 2004. Spectral band difference effects on radiometric cross-calibration between multiple satellite sensors in the Landsat solarreflective spectral domain. Sensors, Systems, And Nextgeneration Satellites Viii, [s.1.], p.1-11.

Teillet P. M., et al., 2007. "Impacts of spectral band difference effects on radiometric cross-calibration between satellite sensors in the solar-reflective spectral domain", Remote Sens. Environ. vol. 110, n. 3, pp. 393-409.

Potter, C. S. et al., 1993. Terrestrial ecosystem production: A process model based on global satellite and surface data. Global Biogeochemical Cycles, [s.1.], v. 7, n. 4, p.811-841.

Potter, C.; Klooster, S.; Genovese, V., 2012. Net primary production of terrestrial ecosystems from 2000 to 2009. Climatic Change, [s.1.], v. 115, n. 2, p.365-378.

Povh, F. P. et al., 2008. Comportamento do NDVI obtido por sensor ótico ativo em cereais. Pesquisa Agropecuária Brasileira, [s.1.], v. 43, n. 8, p.1075-1083.

Purevdorj, T., et al., 1998. Relationships between percent vegetation cover and vegetation indices. Int. J. Remote Sens.

Raun, W., et al., 2001. In-season prediction of potential grain yield in winter wheat using canopy reflectance. Agron. J., 93, 131-138.

Rosa, R., Sano, E. E., 2013. Determinação da produtividade primária liquida (NPP) de pastagens na bacia do rio
Paranaíba, usando imagens MODIS. GeoFocus (Artículos), $n^{\circ} 13-1$, p. 367-395.

Rouse, J.W. et al. Monitoring vegetation systems in the great plains with ERTS. In: Earth Resources Technology Satellite Symposium, 3, 1973, Washington, Proceedings Washington: NASA. p.309-317.

Running, S. W. et al., 2004. A Continuous Satellite-Derived Measure of Global Terrestrial Primary Production. Bioscience, [s.1.], v. 54, n. 6, p.547-560.

Santos, J. S. dos et al., 2014. Identificação da dinâmica espaço-temporal para estimar área cultivada de soja a partir de imagens MODIS no Rio Grande do Sul. Revista Brasileira de Engenharia Agrícola e Ambiental, [s.1.], v. 18, n. 1, p.5463.

Sivasankar, T., et al., 2018. Advances in Radar Remote Sensing of Agricultural Crops: A Review. Int. J. Adv. Sci. Eng. Inf. Technol.

$\mathrm{Yu}$ et al., 2009. Modelling net primary productivity of terrestrial ecosystems in East Asia based on an improved CASA ecosystem model. Int. J. Remote Sens., 30, p. 48514866. 